estatuto de Carlos V para os Países Baixos, de outubro de 1537, o primeiro edito dos Estados e Cidades da Holanda, de 19 de março de 1614, e o das Províncias Unidas de 25 de julho de 1649 etc." (Marx 6, pp. 266-267).

6. As legislações de Eduardo VI, ou melhor, em "um estatuto de seu primeiro governo" (Marx 6, pp. 265-266), de 1547, determinava que "se alguém se recusa a trabalhar, deverá ser condenado a se tornar escravo da pessoa que o denunciou como vadio" (Marx 6, pp. 265-266). O denunciante passava, então, a ter o direito de forçar o denunciado "a qualquer trabalho, mesmo o mais repugnante, por meio do açoite e de corrente" (Marx 6, pp. 265-266). Caso o condenado por vagabundagem não cumprisse essas imposições passaria a ser compreendido como um traidor e, por conseguinte, seria "executado como traidor do Estado" (Marx 6, pp. 265-266). No reinado de Elisabeth, no ano de 1572, a intervenção do aparelho jurídico-político no processo de formação do trabalhador assalariado deu-se nos seguintes termos: "esmoleiros sem licença e com mais de 14 anos de idade devem ser duramente açoitados e terão a orelha esquerda marcada a ferro, caso ninguém os queira tomar a serviço por dois anos" (Marx 6, pp. 265-266), e se tal criminoso não realizar sua inserção no mercado de trabalho até os dezoito anos, este deveria "ser executado [...] sem perdão, como traidor do Estado" (Marx 6, pp. 265-266). No período do governo de Jaime I, o aparelho jurídicopolítico também exerce sua contribuição no processo de formação dos trabalhadores assalariados, estabelecendo que a pessoa que "perambule e mendigue será declarada um malandro e vagabundo" (Marx 6, pp. 265-266). Qualquer pessoa tinha o direito de denunciar esse tipo de crime e os juízes de paz estavam "autorizados a mandar açoitálos publicamente" (Marx 6, pp. 265-266). Nesse governo, os condenados pelo crime de vagabundagem, na primeira vez, eram "encarcerados por seis meses, na segunda por dois anos" (Marx 6, pp. 265-266). E, além do cárcere, esses prisioneiros deveriam "ser açoitados tantos e tantas vezes quanto os juízes de paz" (Marx 6, pp. 265-266) considerassem adequado para a punição de tal crime.

\section{PRÓ-AO-CONTRA, VÁCUO E MATERIALIDADE DA IDEOLOGIA. ENSAIO SOBRE FRAGMENTOS DE ALTHUSSER E PASCAL ${ }^{1}$}

Antônio Herci Ferreira Júnior

Aos moradores da Comunidade Pinheirinho:

assujeitados e sujeitos ideológicos.

Resumo: No artigo “A única tradição materialista”, Althusser $(2,4,5)$ apresenta alguns fundamentos de sua teoria da materialidade da ideologia referenciados explicitamente em Pascal: 1) o pró-ao-contra e a condição material da verdade (que pode tomá-la por contrária sem contraditório); 2) a intuição [sic] do vácuo como assunto filosófico (postulação capaz de negar o substrato para a matéria).

Caracteriza a produção ideológica como um trabalho humano capaz de incorporar as contradições de classe e impregnar diretamente os aparatos ideológicos e postula a necessidade da formulação de uma doutrina dogmática, para combater numa arena de dogmáticos. Apresenta-se aqui uma das ferramentas centrais de tal teoria: o aparato dos corpos - que também tributa a Pascal - efetivamente uma forma de expressar a materialidade da ideologia.

Palavras-chave: aparato dos corpos; transferência; contratransferência; materialismo.

Assim, não podendo fazer com que o que é justo fosse forte, fez-se com que o que é forte fosse justo.

(Pascal 9, §298|103)

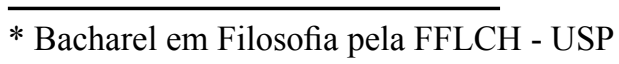


Já havia lido devidamente Pascal no cativeiro. (Althusser 5, p.133)

\section{1.}

Normalmente os textos sobre filósofos ou sobre as filosofias são produzidos sob a notabilidade e importância de um possível resgate, pois tal ou qual movimento de ideias humanas o incita. Talvez em Althusser o mais notável seja que, periodicamente, precisemos retornar aos seus textos para verificar se está morto mesmo!

O que impressionam não são as tentativas de resgatar Althusser. Mas a quantidade de vezes que de fato, metafórica, material ou abstratamente, afirmou-se e reafirmou-se repetidas vezes - como que para constatar que ocorreu mesmo, como fato consumado - a morte, (ultra)passagem e sepultamento dele, para que se pudesse, afinal, selar tudo com uma generosa pá de cal e uma arrojada certeza de fundamentos e independência de consciência.

No entanto, seus textos continuam tendo uma capacidade peculiar de causar incômodo, pois parecem solapar a base para um possível descolamento crítico da ideologia: não obstante a evidente necessidade de fazer a crítica da ideologia, não se pode criticá-la de dentro, pois a visão do observador, neste caso, já se acha comprometida; mas parece não haver lugar fora dela que permita criticá-la.

"A única tradição materialista" é a rubrica sob a qual está etiquetado um conjunto de textos, que Althusser separou de sua famosa "autobiografia", organizados sob três subtítulos: "Espinosa", "Maquiavel" e "Situação política: análise concreta?".

Foram substituídos por um resumo, na primeira edição francesa de L'avenir dure longtemps (3). E publicados pela revista Lignes (2), sob a edição de Baudrillard, como um artigo, no qual constam as duas primeiras seções [Espinosa e Maquiavel], tendo sido mantido o nome original do conjunto e a titulação. Existe ainda uma tradução da primeira parte para o inglês (4).

A edição da Lignes foi integralmente traduzida para o espanhol pela revista Youkali (5), edição referenciada neste trabalho pela disponibilidade, mas principalmente pela primorosa e cuidada edição.

O dogmático pode propor um pensamento libertador ou não? Essa é a pergunta de fundo que permeia todo o artigo.

O texto apresenta-se como uma elegia do dogmatismo, defendido a partir da tese de que é inviável imaginar uma resistência ideológica desancorada de suas condições históricas; provocando aqui aquele malestar citado quanto à possibilidade de nossas mais altas convicções estarem assentadas em nada mais do que afirmações dogmáticas, pois vez ou outra nos vemos compondo essa paisagem, a confundir-nos a certeza do quadro que vemos com a certeza de que estaremos certos no próximo quadro do pensamento, ainda não ocorrido.

A única forma de ancorar - materialmente - a crítica ou análise sobre as condições históricas é, diz o filósofo, recorrendo a uma categoria por definição supra-histórica, a ideologia, já que esta não tem história e manifesta-se sujeitando (ou assujeitando, como se prefere aqui) mesmo antes do surgimento do sujeito, como termo burguês (Althusser 6, p. 210).

A afirmação da ideologia está, por sua vez, vinculada à produção de um discurso que enfrente o dogmatismo em seu próprio campo, afirmando certezas e construindo uma barreira material, um enfrentamento corpo a corpo pelo espaço "do que é o caso", afirma citando Wittgenstein [do Tractatus].

Para Althusser o espaço do Logos e o espaço da ideologia são equivalentes: é o espaço do "ser do movimento e da vida" (Althusser 6, p. 210). O dogmatismo é o aparato da razão que pode materializar a certeza do 
logos e incitar a ação correspondente, sem a qual não existe ação ideológica efetiva: através da repetição e reiteração de verdades ideológicas. Tornar o pensamento palavra e desta fazer um enfrentamento de tal forma que não admita o ajuizamento de seu oponente, pois este seria o caso de uma perda factual, mesmo diante de uma vitória teórica.

Althusser (5, p.134s) argumenta que, para vencer dogmáticos implacáveis como Descartes e Kant; Spinoza e Hegel, respectivamente, devem ser convocados para uma arena dogmática. Reconhecendo, solenemente, integrar esse rol de resistência de dogmáticos, bem como a necessidade de combater ideias falsas com ideias verdadeiras. (Althusser 6, p. 200)

Aponta (Althusser 5, 134) em Espinosa uma estranha e positiva contradição: um espírito profundamente dogmático que pode ser também profundamente libertador!

E do que esse dogmatismo nos libera? Das garras da imaginação e da ilusão, travando um combate com outro dogmatismo! Por isso deve ser firme, pois combate a ilusão e o escamoteamento da verdade.

A novidade, entretanto, é que existe a possibilidade de que, nesse combate por palavras eideias-parte desse processo de libertação-possamos contar com a própria imaginação! A ideologia pode dar consequência material para a imaginação, pois interpela e assujeita historicamente o indivíduo. E faz isso através de um tipo estrito de ação - a ação ideológica - que mobiliza materialmente a certeza cuja verdade não está mais no limite do logos original, pois o extrapolou ao extrapolar sua ideologia.

Althusser parece estar aqui acrescentando algo sutil, mas que muda sensivelmente o caráter que a ideologia adquirira na tradição marxista e funda uma das bases para a sua teoria do aparato dos corpos: o fato de que, além de assujeitados, também somos sujeitos da ideologia, queiramos ou não.
2.

O que me fascinava [em Pascal] era a teoria da justiça e da força, a teoria das relações entre os homens e, sobretudo, a teoria do aparato do corpo (Althusser 5, p.133).

Segundo afirma Althusser, é fato que elas, as ideologias, são materiais. Não porque existam como objetos no mundo, mas porque se EXPRESSAM e ORGANIZAM materialmente a vida das pessoas. Por outro lado, são materialmente a expressão dos indivíduos em sujeitos históricos, movimento explorado mais profundamente em sua teoria da interpelação (Althusser 6 cap. VI, p. 210). Manifesta-se materialmente: através de hábitos, códigos e linguagens, relações de diversos tipos, que compõem a forma de vida.

Tão grande é a força do costume que, daqueles que a natureza fez apenas homens, se fazem todas as condições dos homens (Pascal 9, § 97|634).

A ideologia, entretanto, não é virtual, ou seja, um logos que pensa a sociedade. A ideologia é material: não apenas organiza, mas valoriza e classifica ordens diferentes de espaços, temporalidades, posses e organização para a produção, inclusive do conhecimento e do significado.

Tal ideologia é imposta através de aparatos.

Os nossos magistrados conheceram bem esse mistério. As suas togas vermelhas, os arminhos com que se enfaixam como gatos peludos, os palácios em que julgam, as flores-delis, todo esse aparato augusto era muito necessário. [...]

é mostrar, pelos cabelos, que se tem um criado grave, um perfumista, etc.; pelo ornato, o fio, os passamanes, etc. Ora, não é simples aparato, nem simples arnês, ter vários braços. Quanto mais braços se tem, mais forte se é. Ser elegante é mostrar a própria força (Resp. $\S \S * 82 \mid 44$ e $316 \mid 95$ ). 
Como nos aponta o próprio Pascal, provavelmente sem o saber (mas mantendo a tradição de bastarda às filiações filosóficas) tal aparato não é apenas um aparato. O primeiro é necessário nas formas de significação.

A manifestação ideológica pode operar-se em dois sentidos: pode expressar-se habitualmente da ideologia para o indivíduo, como citado nos casos de interpelação:

Psiu, você aí! (Althusser 6, p. 212).

Mas, se pode convocar indistintamente os indivíduos com argumentos fortes, também sob tais argumentos o indivíduo expressa certezas e convicções:

“É evidente! É mesmo! É mesmo verdade!” (Althusser 6, p. 211)

A individualidade, ainda que assujeitada, também é sujeito ideológico no processo de interpelação. Existe uma convivência entre contrários não contraditórios nesse movimento de interpelação, que permite que Althusser desenvolva a teoria da ação ideológica.

3.

Pascal teria, segundo Althusser (5, p.133), pronunciado a extraordinária [sic] frase: "podemos, sem contradizê-los (aos antigos) afirmar o contrário do que eles diziam! ”. Apresentando, assim, a essência de uma verdadeira teoria da história, pois pode ver que a verdade é dependente e instância ${ }^{2}$ da vida concreta e, justamente por isso, pode revirarse, do pró ao contra, afirmando verdades contrárias não contraditórias. $\mathrm{Ou}$ seja, é referenciada não em suas possibilidades, mas em suas condições materiais de existência histórica.
[...] Sem contradizê-los: porque as condições de nossas experiências científicas mudaram, e já não são as mesmas que a dos antigos. [...]

Frase, infinitamente mais profunda que tudo o que os filósofos do século das luzes puderam dizer (no final muito simples, por teleologia) sobre a história (Althusser 5, p.133).

O contrário não contraditório e a verdade instanciada materialmente segundo os limites das condições materiais incorporam a idéia de uma composição complexa de classe, que agregue contrários ideológicos.

Isso é uma decorrência direta do fato de que não se pode postular, materialmente, uma bipartição efetiva entre os que têm e os que não têm ideologias. A unidade de classe deve ser aceita como é: contraditória e guardando traços contraditórios de diversas ideologias e constituindo-se como unidade ideológica no combate dogmático pela ocupação do espaço.

Pascal, de fato, divide as verdades em dois tipos: as demonstráveis e as indemonstráveis. Essa tese é defendida mais tecnicamente em textos que podem ser encontrados na coletânea Opúsculos (8), por exemplo, em "Resposta ao Pde. Noel", pp. 29s. Toda a seção "Do método das demonstrações geométricas" (pp. 82s) por outro lado tem essa tese das verdades demonstráveis e indemonstráveis como pano de fundo: tenta mesmo desfazer, diante de um público de geômetras, teses consagradas que apontam para a demonstrabilidade de tudo, ou que confundem os campos do demonstrável e não demonstrável.

As demonstráveis são verdades das quais a afirmação de seus contrários geram contradição: este número par é ímpar, por exemplo. As indemonstráveis são as que não são passíveis de demonstração, ou por impossibilidade ou por não ser o caso: as verdades sensíveis, morais ou naturais, por exemplo. 
“O sol nascerá amanhã” não pode ser demonstrado, justamente porque a afirmação de seu contrário, por mais que desafie o bom senso, não é contraditória; “o sol não nascerá amanhã” é uma frase totalmente coerente e compreensível. Ocorre que as verdades mais importantes para a vida humana são da categoria das indemonstráveis. Mas também, por conveniência de algo em nossa própria natureza, são, mesmo que indemonstradas, tomadas como verdades muito certas e seguras: são certezas.

Essa passagem do pró ao contra, em questões que não se pode demonstrar, acontece através da absorção de argumentos e instanciação desses mesmos argumentos ou proposições em escopos mais abrangentes, de tal modo que as antes verdades continuem sendo verdade onde eram, mas o deixem de ser atualmente, sob novas luzes. A não contradição deixa de ser sinal de boa verdade:

A contradição é um mau sinal de verdade: muitas coisas certas são contraditas; muitas coisas falsas ficam sem contradição. Nem a contradição é sinal de mentira, nem a não contradição é sinal de verdade (§384|177).

Além disso, podemos também encontrar em Pascal uma questão sobre materialidade e instanciamento da palavra e seu significado:

Sabem bem, aqueles que possuem o espírito do discernimento, quanta diferença existe entre duas palavras semelhantes, segundo os lugares e as circunstâncias que as acompanham. [...] Todos os que dizem as mesmas coisas não as possuem da mesma maneira (Pascal 8, p. 111).

Segundo Pascal o pensamento por contradição, no campo da moral, tem uma ação particularmente danosa: quando se chega a um impasse ou, com dirá magnificamente Althusser, "quando chega num limite”. Pois nem a afirmação nem a negação são contraditórias e tende-se a considerar que estamos diante de verdades incertas. E que tal incerteza pode ser um sinal de fraqueza, falta de movimento ou ação. Casos em que somos instados a considerar equidistantes as posições consideradas e acabamos por nos iludir que todas as ações humanas também o sejam. Nestes casos, as demonstrações podem ser instrumentos de ocultação das relações de dominação.

Os jesuítas não tornaram a verdade incerta, mas tornaram a impiedade certa. A contradição sempre foi deixada para cegar os maus; pois tudo o que choca a verdade ou a caridade é ruim; eis o verdadeiro princípio (\$902|962).

"A razão, por mais que grite, não pode valorizar as coisas" $(\S 82 \mid 44)$. Existem certezas que não podem ser demonstradas e princípios tais que, quando tomados são verdadeiros, "mas as conclusões são falsas porque os princípios opostos são também verdadeiros" (\$394|619). E justamente aqui é que podemos ver o ÚNICO PONTO forte [sic] dos dogmáticos (se é que têm algum) segundo Pascal:

Que falando de boa fé e sinceramente, não podemos duvidar dos princípios naturais $(\S 434 \mid 131)$.

Mas Pascal, como o sabemos, é antidogmático, chegando mesmo às raias da acusação de cético por isso. Quanto às garras da imaginação, tem um pensamento bastante próprio, pois admite dois sentidos de enganação: dos sentidos para a razão, o tradicionalmente adotado pela filosofia; e da razão para os sentidos, residindo aqui uma particularidade.

Os sentidos, com suas falsas aparências, enganam a razão; e essa mesma fraude que oferecem à razão recebem-na dela, por sua vez $(\S 82 \mid 44)$. 
4.

As verdades em Pascal podem passar ao contrário sem contradição, pois tais verdades são instanciadas em universos mais ou menos amplos de interpretação. Uma primeira afirmação é verdadeira onde está afirmada, mas pode ser negada sem contradizer a sua primeira afirmação onde ela ocorreu, afirmando-a falsa, entretanto, onde ocorre agora. Permitindo assim que se situe a verdade: onde pode ser tomada por verdadeira e onde é falsa; mas principalmente entender as razões dos efeitos que podem cambiá-la de valor, sem cair em contradição. E isso Althusser identificou como traço permanente em si mesmo:

A teoria do hábil e do semi-hábil, a teoria do reconhecimento e do desconhecimento [que] voltaria a encontrar depois em minha própria teoria da ideologia (Althusser 5, p.133).

Parece existir uma gradação na compreensão do que está em jogo, de forma que a primeira negação de uma verdade tem um escopo maior do que a verdade que nega e terá um escopo menor do que a que a negará.

Razão dos efeitos — Graduação. O povo honra as pessoas de grande nascimento. Os semi-hábeis as desprezam, dizendo que o nascimento não é uma vantagem da pessoa, mas do acaso. Os hábeis as honram, não pelo pensamento do povo, mas pelo pensamento oculto. Os devotos, que têm mais zelo do que ciência, as desprezam, malgrado essa consideração que as faz honrar pelos hábeis, porque julgam isso por uma nova luz que a piedade lhes dá. Mas os cristãos perfeitos as honram por outra luz superior. Assim, vão-se sucedendo as opiniões do pró ao contra, segundo a luz que se tem (§337|90).

Em cada hábito ou afirmação habitual de verdade, por outro lado, podemos postular relações que nos remetem a um aparato do corpo que, de forma material instancia valores também em escopos aninhados. Um preceito moral, dessa forma, está sempre acompanhado da força de sua aplicação, ainda que não reconhecível essa força em um outro escopo. Um valor tem, oculto, um aparato que fixa socialmente seu valor.

Razão dos efeitos - Esta é boa: não querem que eu honre um homem vestido de brocado e acompanhado de sete ou oito lacaios! Como! Se o não saudasse, mandava bater-me. Esse hábito é uma força; não acontece o mesmo com um cavalo bem arreado em relação a outro? (\$315|89).

5.

Na genealogia do materialismo, Pascal é destacado pela intuição [sic] de ter incorporado a discussão do vazio como assunto filosófico. Nesta tradição estariam juntos, numa linhagem bastante original: Pascal, Lênin, Freud e Wittgenstein.

Podemos compreender tais autores como autores que - cada um ao seu modo-se insurgem contra o fundamento estabelecido na universalidade, acabam instanciando algo que se supôs ter um valor universal e abalando todo o alicerce da certeza material do mundo.

Lênin questionando a democracia universal, através de sua famosa pergunta: “democracia para quem?". Freud acabando com o mito da universalidade da consciência e Wittgenstein passando com rio [de Heráclito] e tudo sobre o fundamento da própria certeza.

E por que materialista e por que o vácuo é uma intuição dessa linhagem? Porque funda a matéria no nada, ou seja, esvazia dela uma possível substância que não esteja ali. Vejamos o fragmento de Pascal:

Que, horroré [esse do] vácuo? Que haverá no vácuo suscetível de amedrontá-los? Que haverá mais vil e ridículo? Não é 
tudo: mesmo que tenham em si próprios um princípio de movimento para evitar o vácuo, terão braços, pernas, músculos, nervos? $(§ 75 \mid 958)$.

Althusser parece extrair daí uma interpretação materialista de Pascal, justamente por detrás da idéia de vazio. Pois supor um substrato vazio para a matéria está a um passo de esvaziar de fundamentos também as ideias, e torna-las função da impressão.

Não há princípio, por natural que seja, mesmo desde a infância, que não se faça passar por falsa impressão, ou da educação ou dos sentidos.

[...] Porque acreditastes desde a infância que um cofre se achava vazio, por nele não verdes nada", dizem-nos, "acreditais ser possível o vácuo. E uma ilusão de vossos sentidos, fortalecida pelo hábito e que a ciência precisa corrigir," E dizem outros: "Porque vos disseram na escola que o vácuo não existe, corromperam vosso bom senso que o compreendia tão nitidamente, antes dessa má impressão, que cabe corrigir recorrendo à vossa primeira natureza". Quem enganou? O sentido ou a instrução? (§82|44).

Parece que existe uma necessidade de obter segurança sobre as ações da vida e parece que essa segurança vem da crença e do hábito.

O espírito crê naturalmente, e a vontade ama naturalmente; de modo que, na ausência de objetivos verdadeiros, se apegam aos falsos $(\S 81 \mid 661)$.

Ajoelha e reza! Althusser (5, p.133), citando Pascal, parece afirmar que essa crença natural pode transformar-se em força material de uma ideologia, justamente através desse espaço natural que guarda em sua natureza o homem, enquanto materialidade de existência e forma de vida.
A materialidade submete o espírito soberbo, que tudo quer demonstrar; e possibilita, através da materialidade e do hábito, o "entendimento material e sensível" que a interpelação ideológica parece suscitar.

Tal materialidade se expressa, para Pascal, através principalmente da confissão (ou profissão) da fé acompanhado do ato de ajoelhar-se. Esse ato, diz Pascal, é importante em dois sentidos: para os hábeis e para o povo, sabendo-se que são estes dois que compõem o trem do mundo (§273|173).

É preciso que o exterior se junte ao interior [...] isto é, que nos ponhamos de joelhos, oremos movendo os lábios, etc. $[\ldots]$

Ela [a religião cristã] eleva o povo no interior e baixa os soberbos no exterior, não sendo perfeita sem os dois, pois é preciso que o povo entenda o espírito da letra e que os hábeis submetam o seu espírito à letra $(\S \S 250 \mid 944$ e $251 \mid 219)$.

A materialidade do hábito pode expressar a própria materialidade da ideologia mesma, onde reconhecer determinadas verdades sejam, em si, atos!

Mais adiante, seguindo a Espinosa e Pascal neste assunto, eu insistiria veementemente na existência material da ideologia; não apenas em suas condições materiais de existências (suas relações com os interesses, cegados pela imaginação, de um grupo social) que encontramos em primer lugar em Rousseau, em Marx e em numerosos autores, a materialidade de sua própria existência! (Althusser 5, p.138).

E a característica que Althusser aponta que pôde alinhar tais pensadores, é que eles podem "pensar e atuar no limite". No limite 
entre o que seja o pensamento e o que é sua expressão material através do aparato dos corpos.

A força é a rainha do mundo, não a opinião. - Mas a opinião é que usa a força. - A força é que faz a opinião. A fraqueza é bela, segundo pensamos. Por quê? Porque quem quiser andar na corda bamba estará sozinho; e eu arranjarei uma "claque" mais forte com gente que dirá que isso não é decente ( $\$ 303 \mid 554)$.

O povo, diz Pascal, tem opiniões muito sadias, entre elas:

Trabalhar pelo incerto; viajar por mar; passar sobre uma tábua (\$324|101).

Sabendo-se que mesmo o maior filósofo do mundo

[...] sobre uma tábua, por mais larga que seja, se houver embaixo um precipício, embora a razão o convença de sua segurança, a imaginação prevalecerá. Muitos não poderiam pensar sequer nisso sem empalidecer e suar (§82|44).

6.

Tal tipo de posicionamento parece ter encontrado modelos ${ }^{3}$ na realidade das lutas democráticas e populares na América Latina das últimas décadas do século XX: as guerrilhas em El Salvador e Nicarágua, as mobilizações em torno da Teologia da Libertação ou o MST, que levantavam os povos através de algo que pode ser visto como uma ação dos aparatos dos corpos.

Uma das surpreendentes formações de resistência, bastante recorrente nesse aparato dos corpos - nas ocupações de terra, por exemplo
- era a de dispor as mães com filhos de colo nas frentes das manifestações, juntamente com as avós, como se percebe fartamente em um dos mais abrangentes registros de imagens, sonho e poesia legados pelo século das resistências: Terra (10), com imagens de Sebastião Salgado comentadas por Chico Buarque e José Saramago (mas também em vasta bibliografia historiográfica e de relatos). Ressaltando-se, entretanto, que o essencial não está - e nem deveria estar - referenciado.

Um hábito, uma certeza e evidência, portanto uma verdade ideológica - a de salvaguardar o filho - é aqui utilizado paradoxalmente, para constranger o opressor e ocupar um lugar. De fato está-se aqui contando com a força habitual e ideológica que torna tão evidente o argumento da necessidade da preservação, que, suposta universal, é capaz de mobilizarse, tornando indivíduos - sós diante daquele monte de mães - em sujeitos históricos, através do que o filósofo chamou de interpelação.

Vale dizer: soldados que estão sob um aparato de estado, de dominação ideológica (neste caso carregando a concretude do chumbo), mas podem ser vistos como indivíduos convocáveis, que assujeitados tornam-se sujeitos de um rompimento com uma ideologia primeira, em nome de uma ideologia segunda, mas com um valor - o de salvaguardar o filho - que pôde dar valor a tal operação de interpelação.

Apenas a afirmação incondicional da certeza de forma material, ou seja, através do aparato dos corpos, pôde enfrentar a situação com tal ímpeto e arrogância, diante de uma arrogância quase intransponível da força bruta das armas.

Poder-se-ia argumentar sobre a contradição que desumaniza tais frentes de ação, esmagando seus indivíduos e mesmo seus bebês. Afinal já se acreditou que comunistas comessem criancinhas.

As cordas que ligam o respeito de uns para com os outros são em geral cordas de necessidade; pois é preciso que 
haja diferentes graus, porquanto todos os homens querem dominar e todos não podem fazê-lo: alguns, contudo, podem-no $(\$ 304 \mid 828)$.

Assim como podemos aventar muitas razões para mostrar como é retrógrada ou, mais tecnicamente, anacrônica, essa forma, diante de uma outra muito mais evoluída de convocar cidadãos justamente a preservar o que temos de mais precioso: o filho, a grávida, o idoso. Preservar a vida da terra e os direitos do homem. Por fim, teóricos e equipes inteiras poderiam dedicar-se a encontrar, diante de tal fato, os motivos pelos quais estão enfraquecendo os valores todos da sociedade para tal banalização dos corpos! Para gáudio da cabala pirrônica (\$392|109) que logo afirmaria a incerteza da verdade...

As realidades da luta de classes são 'representadas' por 'ideias' que são representadas por palavras. Toda luta de classes pode, às vezes, ser resumida na luta por uma palavra, contra uma outra. Algumas palavras lutam entre si como inimigas. Outras são o lugar de um equívoco: a meta de uma batalha decisiva, porém indecisa. (...) O combate filosófico por palavras é uma parte do combate político (Althusser 1, p. 112).

Essas novas relações de sentido entre o preservado e a preservação estão dispostas à frente de uma multidão que se lhes vem por detrás com bandeiras, foices e enxadas e, surpreendentemente - num primeiro plano antes não notado - alguém tocando uma flauta. As mulheres sorriem, as crianças rolam e atiram-se pelo barranco. Como explicar a contrariedade de que o que deve ser preservado deve ser exposto para a preservação? Como explicar que haja justamente felicidade nesses momentos? Como explicar que, diante de um enterro novamente anunciado de Althusser, possamos esboçar tanta vida que parece inconsciente em seus textos, como ele gostaria de ter dito. Assim como a canção de liberdade viera do cárcere, também poesia parece brotar da toda uma brutalidade.

Grandeza do homem que, mesmo de sua concupiscência, soube tirar um regulamento admirável e fazer um quadro da caridade $(\$ 402 \mid 118)$.

Segundo Althusser (5, pp.146s), atuar no limite pôde ligar todos esses filósofos da única tradição materialista. E atuar no limite é "atuar no risco", "por conta e risco". Ocupar um lugar que ele mesmo confessa que quase nunca soube ocupar direito: "estar só diante da mãe".

Sozinho, mas com os grandes - como Pascal, Freud, Lenin, Wittgenstein. "A lista é infinita, mas encontra-se fechada (exceto por Derrida, a Teologia da Libertação e o pensamento militar)" (Althusser 5, p.146).

\section{REFERÊNCIAS BIBLIOGRÁFICAS}

1.ALTHUSSER, Louis. Aparelhos ideológicos de Estado: notas sobre os aparelhos ideológicos de Estado (AIE). Trad. Walter José Evangelista e Maria Laura Viveiros de Castro. Rio de Janeiro: Graal, 1985.

2._. L'unique tradition matérialiste [1985]. Lignes [Paris], n. 8, pp. 72-119, 1993a.

3._._. L'avenir dure longtemps. Paris: STOCH/IMEC, $1993 \mathrm{~b}$.

4. The only materialist tradition. Part I: Spinoza. In: The new Spinoza. Minneapolis: University of Minnesota Press, 1997.

5. La única tradición materialista. [L'unique tradition matérialiste]. Trad. Juan Pedro García del Campo. Youkali - Revista crítica de Las Artes e El Pensamiento [Madri], n. 4, pp. 132-154, dez. 2007. Edição virtual consultada em agosto de 2011: http://www.youkali.net/youkali4d\%20 Althusser\%20launicatradicionmaterialista.pdf

6. Sobre a reprodução. [Sur la reproduction]. Trad. Guilherme João de Freitas Teixeira. Petrópolis: Vozes. 2o ed., 2008. 
7.OLIVA, Luís César Guimarães. As marcas do sacrifício: um estudo sobre a possibilidade da história em Pascal. Coleção Estudos Seiscentistas. São Paulo: Humanitas, 2004.

8.PASCAL, Blaise. Opúsculos [Coletânea de textos]. Trad. A. Ferreira. Lisboa: Guimarães Editores, 1960.

9. . Pensamentos [Pensées]. Trad. S. Milliet. São Paulo: Abril Cultural, 1973.

10. SAlgAdO, Sebastião; SARAMAgO, José; BUARQUE, Chico. Terra. São Paulo: Companhia das Letras, 1997.

\section{PRO-TO-COUNTER, VACUUM AND MATERIALITY OF IDEOLOGY ESSAY ON ALTHUSSER'S \& PASCAL'S FRAGMENTS}

Abstract: In the article "The only materialist tradition" Althusser $(2,4,5)$ presents some fundamentals of his materiality of ideology theory referenced, explicitly, in Pascal. 1) the pro-to-counter and truth material condition (which can take it for contrary without contradiction); 2) the intuition [sic] of vacuum as a philosophical matter (postulate that is able to deny this substrate to the matter). It characterizes the ideological production as a human work, that is able to incorporate the class contradictions and to impregnate directly the ideological apparatus, and postulates the necessity of formulating a dogmatic doctrine, in order to discuss it in a dogmatic field. It is presented here one of the central tools of such theory: the apparatus of the body - which relies on Pascal too - a mean of expressing the materiality of ideology, effectively.

Keywords: apparatus of the body; transference; counter-transference; materialism.

\section{NOTAS}

1. Utiliza-se aqui apenas o número da referência precedido do símbolo “§” para referenciar os Pensamentos (9) - as poucas citações referenciadas nos Opúsculos (8) serão indicadas. Os números dos fragmentos referem-se, respectivamente, à numeração de Brunschvicg e Lafuma, separados por “"”, seguindo a providencial Tábua de Conversão apresentada pelo professor Oliva em seu livro (7).Na ausência de indicação, as citações de Althusser serão sempre da obra aqui interpretada, A única tradição materialista (5). Os destaques em negrito nas citações são meus, salvo indicação.
2. Instância é aqui é utilizado no sentido de "um contexto ou escopo de interpretação", que pode ser variado e visto sob novas luzes e pontos de vista (re-instanciado). Instanciar é situar uma determinada afirmação ou proposição nesse contexto.

3.Modelo é aqui tomado no sentido que a lógica dá ao termo, segundo o qual se diz que "uma teoria é consistente se apresenta um modelo". 